\title{
Factors That Influence Thrombus Formation in Early Catheter Dysfunction and Success of Alteplase Therapy in Children with Hemodialysis \\ Alexander Jayadi Utama ${ }^{*}$, Partini Pudjiastuti Trihono ${ }^{b}$, Raden Suhartono ${ }^{a}$
}

Introduction: The vascular access modality that is often used to perform regular hemodialysis (HD) measures in children with kidney failure is a tunneled double lumen catheter (TDLC), which has increased its use from 60\% in 2011 to $78 \%$ in 2014 in Indonesia. The incidence of blockage caused by thrombosis is around $50 \%$. These conditions can occur within the first 24 hours after TDLC, and usually develop within two weeks, causing early catheter dysfunction. Alteplase (rt-PA) is a thrombolytic choice for TDLC dysfunction and heparin, streptokinase, and urokinase. This study aims to determine the factors of thrombus formation in early catheter dysfunction and the effectiveness of alteplase as a therapeutic modality.

Method: This study was a case-control study with children aged 0-18 years and suffering from stage 4-5 chronic kidney disease (CKD) who underwent regular HD at Cipto Mangunkusumo National Hospital. Statistical analysis using Mann-Whitney, Chi-square, Fisher's exact, linear regression, and receiver operating characteristic (ROC) statistical tests. The test was carried out using SPSS version 20 for Windows software.

Results: During the period of January 2016 to November 2017, 111 subjects met the criteria. A total of 65 subjects (58.6\%) were male, and 46 subjects (41.1\%) were female. Analysis showed that each albumin level $<3.5 \mathrm{~g} / \mathrm{dL}$, hemoglobin $(\mathrm{Hb})<10 \mathrm{~g} / \mathrm{dL}$, and creatinine $>5 \mathrm{mg} / \mathrm{dL}$ were risk factors for early catheter dysfunction that improved with rtPA $(p<0,05)$. In multivariate analysis, only albumin levels $<3.5 \mathrm{~g} / \mathrm{dL}$ were associated with early catheter dysfunction. Receiver operating characteristics (ROC) curves show that early catheter dysfunction is at risk of albumin levels with a cutoff of $\leq 3.71 \mathrm{~g} / \mathrm{dL}$ (sensitivity of $90.9 \%$ and specificity of $52.5 \%$ ) and $\mathrm{Hb}$ levels with a cutoff of $\leq 8.58 \mathrm{~g} / \mathrm{dL}$ (sensitivity $54.5 \%$ and specificity $77.5 \%$ ). Rt-PA therapy successfully improves the condition of early catheter dysfunction in $20 / 22(90.9 \%)$ cases. There were no significant side effects on the use of rt$\mathrm{PA}$ in this study.

Conclusion: In children undergoing regular HD with TDLC, hypoalbuminemia $<3.5 \mathrm{~g} / \mathrm{dL}, \mathrm{Hb}$ $<10 \mathrm{~g} / \mathrm{dL}$, and creatinine $>5 \mathrm{mg} / \mathrm{dL}$ were risk factors for early catheter dysfunction.

Alteplase may be useful as a safe therapeutic option.

Keywords: tunneled double lumen catheter in children, early catheter dysfunction, rt-PA https://doi.org/10.36864/jinasvs.2020.2.005

*Correspondence: alexander.jayadi@ui.ac.id

aM.D., Vascular and Endovascular Division, Department of Surgery, Cipto Mangunkusumo Hospital - Faculty of Medicine, Universitas Indonesia, Jakarta, Indonesia

${ }^{b}$ M.D., Ph.D., Nephrology Division, Department of Pediatric, Cipto Mangunkusumo Hospital - Faculty of Medicine, Universitas Indonesia, Jakarta, Indonesia

\section{INTRODUCTION}

Chronic kidney disease (CKD) in children can be caused by congenital abnormalities such as congenital hypoplasia or renal dysplasia, uropathic obstruction (such as posterior urethral valves), and acquired diseases such as glomerulonephritis. The vascular access modality that is often used for hemodialysis in children is tunneled double lumen catheter (TDLC), which has increased its use from $60 \%$ in 2011 to $78 \%$ in 2014 from all options for vascular access untunneled catheter, tunneled catheter, arteriovenous fistula (AVF) and arteriovenous graft (AVG)). The duration of use of TDLC in children with a period of one year only reaches $60-85 \%$, and the average usage is 110 days. The use of TDLC as HD access for children in Cipto Mangunkusumo National Hospital in 2016 there were 39 patients. $^{1}$

Problems that arise in the use of TDLC are blockages and infections. An obstruction is caused by thrombosis, which occurs in $14-36 \%$ of patients within one to two years after catheter placement. This thrombosis causes catheter dysfunction. The 
incidence of blockage caused by thrombosis is around $50 \%$. These problems are influenced by the location of the tip of the catheter and the position of the installation. ${ }^{2,3}$

Complications in the use of a double lumen catheter are divided into two, which are infection and non-infection, a cause of increased morbidity and mortality in populations of children with chronic kidney disease. This complication can occur during catheter placement or catheter use. ${ }^{4}$

Catheter dysfunction can also be caused by improper catheter tip position, which causes inadequate blood flow. A fluoroscopy is needed To determine the location of the catheter tip when installing the catheter. The catheter tip should be in the superior vena cava, cavoatrial junction, or in the right mid atrium to get a good flow. However, placement of the tip of the catheter in the superior vena cava or cavoatrial junction causes more catheter dysfunction than the installation of the tip of the catheter in the mid atrium $(0.84$ vs. $0.35 ; p=0.006) .^{5}$ At Cipto Mangunkusumo National Hospital research on placement, the position of the catheter tip during the period August 2012 to August 2016 found 55 subjects who met the criteria; 32 subjects $(58.2 \%)$ were male, and 23 subjects $(41.8 \%)$ were female. The average duration of use of a 125-day TDLC. The length of use of TDLC in the catheter tip position group in the mid atrium was longer than in the catheter tip position group outside the right atrium mid, which was 154 $(20-491)$ days compared to 86.5 (35-228) days ( $P$ $<0.05)$ respectively. ${ }^{1}$

Patients using TDLC can experience a blockage in the catheter. This is caused by thrombosis due to the direct effect of veins, blood flow, and catheter location. These blockages consist of three types, namely the formation of fibrin layers (fibrin sheath), intraluminal blood clots, and venous thrombosis. The fibrin sheath structure is a combination of fibrinogen, lipoprotein, albumin, and coagulation factors that begin to occur 24 hours after catheter placement. The blockage makes bacterial colonization and causes infection. Such blockages and infections cause morbidity in patients, and hemodialysis access is ineffective. ${ }^{6,7}$

From the description above, we need a study to determine the factors that influence early catheter dysfunction, as well as the effectiveness of rt-PA in early catheter dysfunction in hemodialysis patients in children.

\section{METHOD}

The design of this study used a case-control that examines the relationship between central venous catheter dysfunction due to thrombosis in long-term dialysis catheters. The study was conducted in the Division of Vascular and Endovascular Surgery Department of Surgery and Nephrology Division of the Department of Pediatric Health Sciences Cipto Mangunkusumo National Hospital from January 2016 to December 2017.

The study population was pediatric patients aged $0-18$ years who were diagnosed with chronic kidney disease stage 4-5 who underwent hemodialysis at Cipto Mangunkusumo National Hospital, who performed double lumen catheter placement with fluoroscopy with tip position in the right mid atrium and underwent early dysfunction catheter, then received rt-PA therapy. The method of taking the subject was done by taking all cases of hemodialysis in long-term double lumen catheter placement using fluoroscopy with tip position in the right mid atrium and patients given rt-PA therapy if there was catheter dysfunction without matching between case groups and control groups, in Division of Vascular and Endovascular Department of Surgery and Pediatric Health Sciences at Cipto Mangunkusumo National Hospital in 2016-2017.

\section{RESULTS}

Data of research subjects were obtained through medical record data, patients undergoing double-lumen tunneling catheter who had early catheter dysfunction, and received rt-PA therapy and HD monitoring form of pediatric kidney center at Cipto Mangunkusumo National Hospital within January 2016 to November 2017 obtained 111 the subject.

Of the 111 subjects included in this study, the mean age of the subjects was $12.8 \pm 4.57$ years, ranging from 1 to 18 years. Based on sex, there were 65 subjects $(58.6 \%)$ male and 46 subjects $(41.4 \%)$ female. The underlying disease that caused CKD was 58 subjects $(52.3 \%)$ caused by inflammatory diseases and 53 subjects $(47.7 \%)$ caused by anatomical abnormalities. The nutritional status of patients based on the Z-score at the age of $5-18$ years found 12 subjects $(10.8 \%)$ severe wasted, 15 subjects $(13.5 \%)$ wasted, 61 subjects (55\%) normal, 17 subjects $(15.3 \%)$ overweight, and six subjects $(5.4 \%)$ were obese. The mean albumin level in patients who received rt-PA therapy was $2.9 \pm 0.833 \mathrm{~g} / \mathrm{dL}$, while patients who did not receive rt-PA treatment were $3.7 \pm 0.909 \mathrm{~g} / \mathrm{dL}$. The mean hemoglobin level in patients who received rt-PA therapy was $8.9 \pm 1.82$ $\mathrm{g} / \mathrm{dL}$, whereas patients who did not receive rt-PA treatment was $10.6(\mathrm{SD}=1.82) \mathrm{g} / \mathrm{dL}$ (Table 1$)$.

In receiver operating characteristics (ROC), the sensitivity and specificity of albumin were obtained with a cutoff at $\leq 3.71(p<0.001)$.

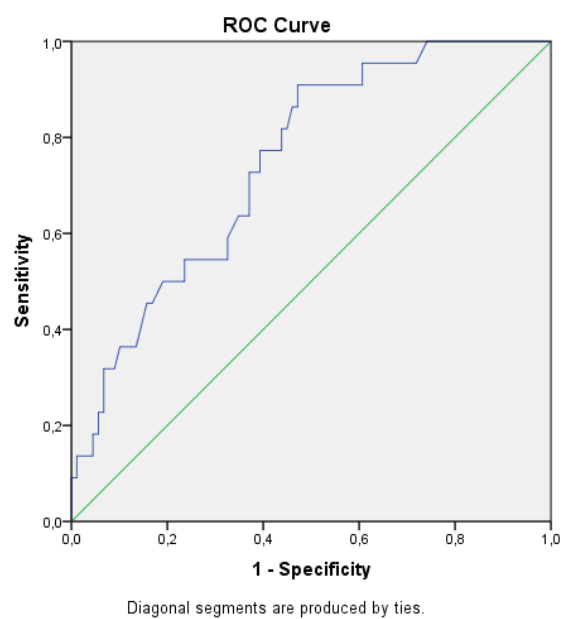

Figure 1. Receiver operating characteristic (ROC) with albumin and hemoglobin as factors affecting thrombus formation in early catheter dysfunction.

In receiver operating characteristic (ROC), the sensitivity and specificity of hemoglobin were obtained with a cutoff at $\leq 8.58(p=0.003)$. 


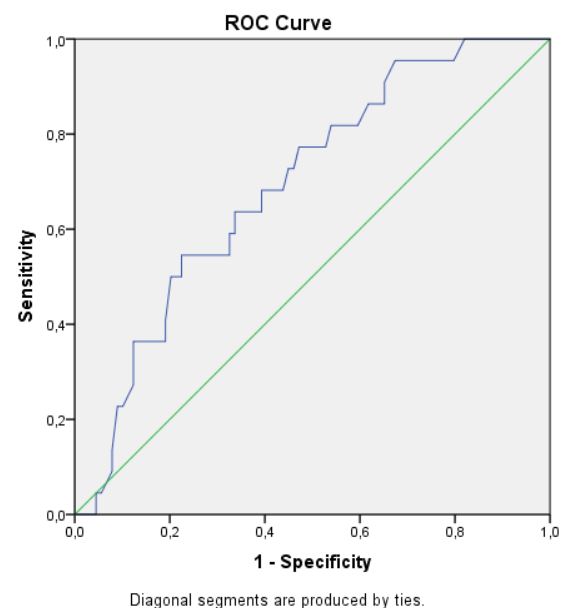

Figure 2. ROC analysis of hemoglobin as a factor affecting thrombus formation in early catheter dysfunction.

\section{DISCUSSION}

The use of TDLC for regular HD in children is associated with several complications, including dysfunction, infection, malposition, venous thrombosis, and venous stenosis. These complications cause the catheter to be removed or replaced. Several attempts were made to overcome or reduce the incidence of complications so that the optimal use of the catheter could be reached. Following the recommendations issued by KDOQI, the recommended position in TDLC installation is through the right internal jugular vein with the tip of the catheter in the mid-right atrial region, so that blood flow during HD can be maximized. ${ }^{8}$

The length of use of the catheter is related to the morbidity and costs of patient care. The longer TDLC can be used, the patient's morbidity will be lower, because to replace TDLC requires invasive action. Besides, TDLC replacement will also increase maintenance costs because it covers the costs of buying a new TDLC.

The position of the tip of the catheter recommended by KDOQI is in the mid-right atrial

Table 1. Characteristics of research subjects

\begin{tabular}{|c|c|c|c|}
\hline Variable & $\begin{array}{l}\text { Thrombus } \\
(\mathrm{N}=22)\end{array}$ & $\begin{array}{l}\text { No thrombus } \\
(\mathrm{N}=89)\end{array}$ & $P$ \\
\hline Age (years old) & $12(1-17)$ & $14(1-18)$ & \\
\hline \multicolumn{4}{|l|}{ Gender } \\
\hline Male & $14(21 \%)$ & $51(78,5 \%)$ & 0,581 \\
\hline Female & $8(17,4 \%)$ & $38(82,6 \%)$ & \\
\hline \multicolumn{4}{|l|}{ Nutritional status } \\
\hline Wasted + severely wasted & $6(22,2 \%)$ & $21(77,8 \%)$ & 0,718 \\
\hline Normal + overweight + obese & $16(19,0 \%)$ & $68(81,0 \%)$ & \\
\hline \multicolumn{4}{|l|}{ Albumin } \\
\hline$<3,5 \mathrm{~g} / \mathrm{dL}$ & $16(32,0 \%)$ & $34(68,0 \%)$ & 0.004 \\
\hline$\geq 3,5 \mathrm{~g} / \mathrm{dL}$ & $6(9,8 \%)$ & $55(90,2 \%)$ & \\
\hline \multicolumn{4}{|l|}{ Haemoglobin } \\
\hline$<10 \mathrm{~g} / \mathrm{dL}$ & $17(28,8 \%)$ & $42(71,8 \%)$ & 0.011 \\
\hline$\geq 10 \mathrm{~g} / \mathrm{dL}$ & $47(90,4 \%)$ & $5(9,6 \%)$ & \\
\hline \multicolumn{4}{|l|}{ Underlying disease } \\
\hline Glomerulonephritis & $13(51,9 \%)$ & $45(50,6 \%)$ & 0,488 \\
\hline Anatomic abnormality & $9(40,9 \%)$ & $44(49,4 \%)$ & \\
\hline
\end{tabular}

Table 2. Multivariate analysis of factors affecting thrombus formation in early catheter dysfunction

\begin{tabular}{lll}
\hline Variable & OR & $\mathrm{P}$ \\
\hline Median, Albumin & & \\
Median, Creatinin & 0,308 & 0,001 \\
Median, Haemoglobin & 1,041 & 0,245 \\
Etiology & 0,843 & 0,88 \\
$\quad$ Inflammation & 0,423 & 0,164 \\
$\quad$ Anatomic & referensi & \\
Z score & & 1,215 \\
$\quad$ Wasted + severely wasted & $-1,215$ & \\
$\quad$ Normal + overweight + obese & referensi & \\
\hline
\end{tabular}

Table 3. Success rates for using rt-PA.

\begin{tabular}{llllll}
\hline & \multicolumn{2}{c}{ Outcome after rt-PA } & P & RR \\
& Successful & Unsuccessful & Total & & \\
\hline Thrombus & $20(90,9 \%)$ & $2(9,1 \%)$ & $22(100 \%)$ & 0.038 & $0,90(0,79-1,03)$ \\
No thrombus & $89(100 \%)$ & 0 & 89 & & \\
\hline
\end{tabular}


region because if the location of the TDLC tip is outside the mid-right atrium or is in the superior vena cava, it can cause complications, including vena cava thrombosis and catheter dysfunction. This can be seen from the results of the analysis of factors related to the length of use of tunneled double lumen catheter in children with regular hemodialysis in 2017 with the duration of use of TDLC mounted on the right jugular vein was longer clinically and statistically compared to that installed in the left jugular vein (163 (163) 20491) vs. $94.5(49-194) ; \mathrm{P}<0.05)$ and TDLC at the position of the catheter tip in the right middle atrium had a longer duration of clinical and statistical use of TDLC compared to those outside the right mid atrium

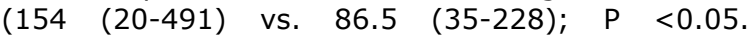
Fluoroscopy can be used to direct the position of the tip of the catheter in the right mid-atrium. ${ }^{8-10}$

Management of occlusion in TDLC caused by thrombus remains unclear. The Kidney Disease Outcomes Quality Initiative (KDOQI) provides recommendations for using urokinase in catheter malfunctions, $70-90 \%$ effective. ${ }^{8}$ Other thrombolytic alternatives that can be used in catheter malfunctions caused by thrombus are streptokinase and alteplase with $70-90 \%$ are effective. However, the use of streptokinase causes many allergic problems and an increase in antibody formation. In the use of alteplase, the rate of allergic reaction is minimal $(0.02 \%)$, and there are no reports of antibody formation, so the use of alteplase in TDLC malfunctions caused by thrombus is a safe alternative to use. ${ }^{11,12}$

Timoney et al. stated that the use of alteplase gave good results on CVC occlusion in oncology patients (81\%). Marcela L. Mendes et al., stated that the use of $1 \mathrm{mg} / \mathrm{mL}$ alteplase in TDLC occlusions was very safe and effective. Haire et al., gave his research report that the use of alteplase in TDLC occlusions gave better results compared to patients using urokinase. ${ }^{13}$ In this study, a $90.9 \%$ success rate was found in patients with thrombus occlusion caused by the thrombus, where alteplase therapy was given by the method push/pause.

The current research is not an easy one because the management of TDLC occlusion is focused not only on saving occlusion in TDLC but also on maintaining maximum blood flow during dialysis.

Brenda et al., from his study, stated that in patients undergoing hemodialysis, rt-PA use once a week as a locking fluid compared to heparin three times a week showed a significant reduction in the occurrence of TDLC malfunction due to thrombus and bacteremia. The rate of bleeding or other adverse conditions in patients using alteplase does not increase. Thrombolytic therapy is used for TDLC malfunctions in both catheter nondialysis and catheter dialysis. Thrombolytic treatments such as rt-PA bind fibrin better and activate plasminogen at the end of the thrombus to form plasmin, which dissolves fibrin in the thrombus and prevents fibrinogen from forming more fibrin. Management of TDLC treatment for bacteremia is costly, with the use of rt-PA can reduce the risk of complications without increasing the occurrence of bleeding is very important. ${ }^{14}$

In this study, it was found that albumin levels, hemoglobin levels, and creatinine significantly affected the occurrence of thrombus. Whereas with multivariate calculations, the results of albumin levels were significant.

Plasma levels of fibrinogen as markers in thrombosis, including $\mathrm{D}$-dimers and prothrombin 1 and 2 fragments, are found increased in hypertensive patients with decreased creatinine clearance. ${ }^{1}$ Red blood cells add platelet function by releasing adenosine diphosphate (ADP) with inactivation of vascular prostacyclin and by changing rheumatoid factor clearance, resulting in an interaction between platelets and blood vessel walls. ${ }^{15}$ So anemia plays an important role in platelet dysfunction in CKD patients. So that the administration of recombinant erythropoietin (EPO) is not only to improve platelet function but is also used to improve platelet and hemostatic function. However, some opinions are stating that the use of recombinant EPO is related to the formation of thrombus. In some studies, the effects of recombinant EPO on hemodialysis of thrombus access have had conflicting results. ${ }^{16}$

There are many mechanisms of inflammation that cause vascular disease. Inflammation is related to changes in the state of blood vessels and platelet adhesion molecules, the structure and concentration of lipoproteins on coagulation factors, and oxidant and antioxidant activities. ${ }^{17}$ In patients with chronic renal failure, chronic and recurrent inflammatory conditions occur. Hypoalbuminemia is an essential prediction of mortality in patients with CKD. Hypoalbumin is not only a predictor of a state of malnutrition but is also the result of an inflammatory state. ${ }^{18}$

Marcela LM et al., stated that the use of alteplase $1 \mathrm{mg} / \mathrm{mL}$ is a safe and effective way of occlusion of TDLC in hemodialysis patients. ${ }^{19}$

The strength of this study is that there has been no successful study of hemodialysis of rt-PA therapy in early catheter dysfunction caused by thrombus and the factors that influence it. The strength of this study is that it evaluates things that have never been done in other studies, specifically in pediatric patients. The weakness of this study is that it has not assessed the effectiveness of rt-PA to maintain maximal blood flow in patients with hemodialysis and the rate of infection. In this study also has not been able to calculate the cost of using Rt-PA when compared with the use of other antithrombotics.

\section{CONCLUSION}

Factors that play a role in the occurrence of early catheter dysfunction caused by thrombus were albumin levels less than $3.7 \mathrm{~g} / \mathrm{dL}$ and hemoglobin levels less than $8.5 \mathrm{~g} / \mathrm{dL}$. Glomerulonephritis and poor nutritional status did not affect the occurrence of early catheter dysfunction caused by thrombus. Alteplase (rt-PA) can be used as therapy in patients with early catheter dysfunction caused by a thrombus with a low and safe bleeding rate. The use of rt-PA can reduce morbidity and mortality in CRF patients because it reduces repair to TDLC. Further research related to the effectiveness of rt-PA as a thrombus prophylaxis, maintaining maximal blood flow (Qb) in hemodialysis patients who have received rt-PA therapy due to early catheter dysfunction caused by thrombus, and costeffective assessment of the use of rt-PA as therapy and prophylaxis in early catheter dysfunction caused by thrombus.

\section{CONFLICT OF INTEREST}

The author states the original work, and there is no conflict of interest in doing this research. 


\section{ORCID ID OF AUTHORS}

Alexander Jayadi Utama

https://orcid.org/0000-0003-2922-6487

Partini Pudjiastuti Trihono

https://orcid.org/0000-0003-2893-6049
Raden Suhartono

https://orcid.org/0000-0002-9142-3062

\section{REFERENCES}

1. Catena C, Zingaro L, Casaccio D, Sechi LA: Abnormalities of coagulation in hypertensive patients with reduced creatinine clearance. Am J Med 109:556-561, 2000.

2. Baskin JL, Pui $\mathrm{CH}$, Reiss $\mathrm{U}$. Management of occlusion and thrombosis associated with long-term indwelling central venous catheters. Lancet. 2009;374(4):159-69.

3. Male $C$, Chait $P$, Andrew M, Hanna K, Julian J, Mitchell L. Central venous line-related thrombosis in children: association with central venous line location and insertion technique. Blood. 2003;101(11):4273-8.

4. Mutin M, Canavy I, Blann A, Bory M, Sampol J, Dignat-George F : Direct evidence of endothelial injury in acute myocardial infraction and unstable angina by demonstration of circulating endothelial cells. Blood 93: 2951-2958,1999.

5. Liu ETH, Venkatesh SK, Vathsala A. Hemodialysis catheters - from placement to complications : our experience. European Society of Radiology. 2010:1-34.

6. Faintuch S, Salazar GMM. Malfunction of dialysis catheters: management of fibrin sheath and related problems. Tech Vasc Interv Radiol. 2008;11(3):195-200.

7. Fadrowski JJ, Hwang W, Neu AM, Fivush BA, Furth SL. Patterns of use of vascular catheters for hemodialysis in children in the united states. Am J Kidney Dis. 2009;53(1):91-98.

8. National Kidney Foundation. KDOQI clinical practice guidelines and clinical practice recommendations for 2006 updates: hemodialysis adequacy, peritoneal dialysis adequacy and vascular access. Am J Kidney Dis. 2006; 48:S1-322.

9. Baskin KM, Jimenez RM, Cahill AM, Jawad AF, Towbin RB. Cavoatrial junction and central venous anatomy: implications for central venous access tip position. J Vasc Interv Radiol. 2008;19(3):359-65.

10. Engstrom BI, Horvath JJ, Stewart JK. Tunneled internal jugular hemodialysis catheters: impact of laterality and tip position on catheter dysfunction and infection rates. J Vasc Interv Radiol. 2013;24(9):1295-302.

11. Genentech Inc, Activase (Alteplase, Recombinant) [product information brochure]. South San Francisco, CA : Genentech, Inc, 1999.

12. Davis SN, Vermeulen L, Schwartz BS, et al. Activity and dosage of alteplase dilution for clearing occlution of venous-access devices. Am J Health Syst Pharm 2000;57:1039-45.

13. Timoney JP, Malkin MG, Leone DM, et al. Safe and cost effective use of alteplase for the clearance of occluded central venous access devise. J Clin Oncol 2002;20: 1918-22

14. Brenda RH, Louise MM, Charmaine EL, Marcello T, et al. Prevention of Dialysis Catheter Malfunction with Recombinant Tissue Plasminogen Activator. The New England Journal of medicine 364;303-312, 2011.

15. Casati S, Passerini P, Campise MR, Graziani G, Cesana B, Perisic M, Ponticelli C : Benefits and risks of protacted treatment with human recombinant erythropoietin in patients having haemodialysis. $\mathrm{Br}$ Med J ClinRes Ed 295: 1017 - 1020, 1987.

16. Winearls CG, Oliver DO, Pippard MJ, Reid C, Downing MR, Cotes PM : Effect of human erythropoietin derived from recombinant DNA on the anaemia of patients maintained by chronic haemodialysis. Lancet 2: $1175-1178,1986$.

17. Kaysen GA : The microinflamatory state in uremia : causes and potential consequences. J Am Soc Nephrol 12: 1549-1557,2001.

18. De Marchi S, Falleti E, Giacomello R, Stel G, Cecchin E, Sepiacci G, Bortolotti N, Zanello F, Gonano F, Bartoli E : Risk factors for vascular disease and arteriovenous fistula dysfunction in hemodialysis patients. J Am Soc Nephrol 7:1169-1177,1996.

19. Marcela L. Mendes, Joao HC, Tricya N et.al. Effective Use of Alteplase for Occluded Tunneled Venous Catheter in Hemodialysis Patients. Artificial Organs 38(5):399-403, 2014. 